deficiency than serum iron and iron binding capacity, which show considerable overlap between healthy and iron deficient populations. ${ }^{2}$ The review included 55 studies in which laboratory results and histological bone marrow findings were available for at least $50 \%$ of identifiable patient groups. Serum ferritin was by far the most powerful diagnostic test (area under receiver operating characteristic (ROC) curve, 0.95); however, as can be predicted from the physiology and biochemistry of the acute phase response in inflammation (which influences serum iron, transferrin, and ferritin concentrations), the test properties were different in patients with inflammatory, liver, or neoplastic disease compared with other patients. This accounts for the different diagnostic thresholds incorporated in the guidance for patients with these diseases, and the role of a therapeutic trial of iron in borderline situations (deficiency being confirmed by a rise in serum haemoglobin in response to iron). The British Columbia guidelines include adding assays of serum iron and iron binding capacity if serum ferritin is not diagnostic in a patient with chronic inflammation. ${ }^{5}$ It is not clear from published work whether this addition is superior to the pragmatic policy of a therapeutic iron challenge. An alternative approach is to undertake a bone marrow biopsy to assess iron stores. However, this is rarely necessary providing a blood film has been examined to exclude a myelodysplastic syndrome.

Finally, there seems to be no reason to question the guidance on establishing the cause of the iron deficiency, and, in view of the possibility of malignancy as the underlying cause, it would not be appropriate to subject this to a trial in patients. Extensive investigation could reasonably be considered unnecessary in patients at low risk of malignancy when the doctor is confident of the clinical diagnosis-such as hypermenorrhea in a young woman with heavy menses.

1 Guyatt GH, Patterson C, Ali M, Singer J, Levine M, Turpie I, et al. Diagnosis of iron deficiency in the elderly. Am J Med 1990;88:205-9.

2 Guyatt GH, Oxman AD, Ali M, Willan A, Mcllroy W, Patterson C. Laboratory diagnosis of iron deficiency anaemia. J Intern Med 1992;7:145-53.

3 Cash JM, Sears DA. The anaemia of chronic disease: spectrum of associated diseases in a series of unselected hospitalized patients. Am J Med 1989;87:638-49.

4 Griner PF. Haematological problems-microcytosis. In: Black ER, Bordley DR, Tape TG, Panzer RJ, eds. Diagnostic strategies for common medical problems. 2nd ed. Philadelphia: American College of Physicians, cal problems.

5 British Columbia Medical Association Guidelines and Protocols Advisory Committee. Investigation and management of iron deficiency: revised 2004. www.healthservices.gov.bc.ca/msp/protoguides/gps/ irondef.pdf (accessed 11 Aug 2006).

6 Smellie WSA, Forth J, Bareford D, Twomey P, Galloway MJ, Logan ECM, et al. Best practice in primary care pathology: review 3.J Clin Pathol 2006:59:781-9.

7 Goddard AF, McIntyre AS, Scott BB. Guidelines for the management of iron deficiency anaemia. Gut 2000;46(suppl 3-4):IV1-5.

8 Thomas RE, Croal BL, Ramsay C, Eccles M, Grimshaw J. Effect of enhanced feedback and brief educational reminder messages on laboratory test requesting in primary care: a cluster randomised tial. Lame $2006 \cdot 367: 1990-6$.

(Accepted 13 September 2006)

doi 10.1136/bmj.38979.358032.BE

\title{
Anaesthesia, Elvis, and lawnmowers
}

I was interested to see my specialty in the daily "listed" feature in the Guardian newspaper, which, on 13 September 2006 , nominated the following "specialist museums": Anaesthetic Museum, Barts and The London NHS Trust; Business Card Museum, Pennsylvania, USA; Decoy Duck Museum, Maryland, USA; Dog Collar Museum, Leeds Castle; "Elvis is alive" Museum, Missouri, USA; Hair Museum, Missouri, USA; British Lawnmower Museum, Southport; Museum of Questionable Medical Devices, Minnesota, USA; Mushroom Museum, Saumur, France; Pencil Museum, Cumbria; Potato Museum, Brussels; Quilt Museum, Massachusetts, USA; Sock Museum, Sakata, Japan; Typewriter Museum, West Virginia, USA.

Although I certainly cannot argue with an anaesthetic museum being specialist, I thought it was an interesting association to be listed with the Museum of Questionable Medical Devices (www.mtn.org/quack), which includes a foot operated breast enlarger that sold four million in the 1970s and a chair that shakes violently and is uncomfortable to sit in (from the same sanatorium that invented Kellogg's Corn Flakes). The museum at Barts and the London is not, in fact, a museum of anaesthesia but of the history of Barts itself, although I was told that one of the consultants has a private collection. There is, however, a well kept anaesthetic museum at the Association of Anaesthetists of Great Britain and Ireland, 21 Portland Road, London, which is open to the public.

At the risk of belittling the importance of socks and potatoes, I couldn't help getting the impression that the Guardian's list was of things that might be expected to be too trivial to warrant a museum. Should it be unexpected that anaesthesia is grouped together with exhibitions of dog collars and lawnmowers? My university educated father was surprised to find that there is even one monthly journal devoted solely to the practice of anaesthesia. When I stated my commitment to my specialty my grandfather hoped that I was also keeping up my interest in medicine. When my former girlfriend, who had a PhD in biological science, received an anaesthetic she presumed that the induction dose was also the maintenance of anaesthesia, that the anaesthetist had to estimate the amount to cover the whole duration of surgery, and that the anaesthetist's job was pretty much over after that.

I think that, for many people, anaesthesia is as complicated as a cloth soaked in chloroform used to facilitate abduction of the pretty blonde victim in the A-Team, who, of course, is never seriously harmed in the process. It is an event that provokes much fear and anticipation beforehand. When it happens, only the instant of losing consciousness is remembered, and afterwards it is as though nothing has happened-so long as the antiemetics and analgesia have worked. It is perhaps counter intuitive to many that this practice should require a medical degree and then years of postgraduate training.

In Zambia when you leave medical school it is impossible to train as an anaesthetist without leaving your country. You can become an obstetrician, but only non-physician medical officers can train to anaesthetise for caesarean sections. Anaesthetic pay is poor-even in the private sector it is just $10 \%$ of the modest fee, whereas the surgeon gets $55 \%$. No medical student wants to become an anaesthetist, with the consequence that anaesthesia (and intensive care and pain management) is undervalued. Patients suffer as a consequence, and it is difficult to see an end to this vicious circle.

I'm fortunate that I don't have to worry about appreciation by my colleagues in the same way that the few physician anaesthetists in Zambia do. Consequently, when people ask me what I do at dinner parties, I run the risk of them underestimating the full extent of my education but I never had to think twice about choosing this challenging, enjoyable, and useful specialty.

M Dylan Bould specialist registrar, Great Ormond Street Hospital, London(dylanbould@yahoo.co.uk) 